\title{
Evaluation of MONJU Core Damage Risk due to Control Rod Function Failure*
}

\author{
Masutake SOTSU** and Kenichi KURISAKA*** \\ **Plant Dynamics Analysis Group, FBR Plant Engineering Center, Japan Atomic Energy Agency, \\ 1, Shiraki, Tsuruga, Fukui, 919-1279 Japan \\ E-mail: sotsu.masutake@jaea.go.jp \\ ***Safety Evaluation Group, FBR System Engineering Unit, Advanced Nuclear System Research \\ and Development Directorate, Japan Atomic Energy Agency, \\ 4002, Narita, Oarai, Ibaraki, 311-1393 Japan \\ E-mail: kurisaka.kennichi@jaea.go.jp
}

\begin{abstract}
MONJU is a sodium-cooled, loop-type prototype fast breeder reactor with three primary cooling loops that can supply $280 \mathrm{MW}$ of electricity. The limiting conditions of operation defined in the safety regulations for MONJU given the allowed outage time were evaluated by a probabilistic safety assessment technique in our previous study. If a function failure is found in a control rod, certain measures are required by the safety regulations. In this case, if it is confirmed within $24 \mathrm{~h}$ that no other control rods are stuck, reactor operation is allowed to continue. To assess the validity of the $24 \mathrm{~h}$ allowable time in view of core damage risk, it is necessary to analyze the conditions to be changed when a stuck rod is discovered. Furthermore, to develop a method for evaluating the probability of a control rod insertion failure, it is necessary to re-estimate the frequency of core damage under control rod insertion failure conditions. This paper describes a method for this re-estimation. The probability of an insertion failure of one control rod has been calculated by applying Jeffrey's noninformative prior distribution by considering insertion times based on the results of a mock-up test. The necessary rod insertion numbers for the main reactor shutdown and backup shutdown systems were considered. The results showed that a completion time of $24 \mathrm{~h}$ gives a safety margin comparable to that of the Incremental Conditioned Core Damage Probability, that is, an acceptable risk threshold represented by the U.S. Nuclear Regulatory Commission RG 1.177. Thus, the timeframe defined in the present safety regulations was concluded to be appropriate.
\end{abstract}

Key words: FBR, MONJU, PSA, AOT, LCO, Common Cause Failure, Control Rod Stuck

\section{Introduction}

If a piece of important equipment fails, we need to know whether the countermeasures taken after the discovery of failure and the time necessary to complete them are appropriate or not to control damage risk. In general, in the safety guidelines based on technical specifications, equipment related to safety functions (i.e., reactor shutdown, cooling, and containment) is defined as part of the safety system along with the countermeasures to mitigate function failure [1]. The countermeasures and the time to complete them are also established in the safety guidelines on the basis of an engineering approach.

So far, according to several methodological guidelines [2-5], the allowed outage time (AOT) for these safety systems, which contribute to the prevention or mitigation of core 
damage frequency (CDF), can be evaluated through the results of a level 1 probabilistic safety assessment (PSA). The limiting conditions of operation (LCO) in the safety guidelines specific to each nuclear power station define these countermeasures and AOTs. The influence of the failures of these systems is estimated by calculating $\triangle \mathrm{CDF}$ in which the failure probability value for an intended system is 1 .

Sotsu and Kurisaka estimated the contribution of AOT to the CDF for the Japanese prototype fast breeder reactor MONJU [6] [7]. MONJU is a sodium-cooled, loop-type prototype fast breeder reactor with three primary cooling loops that can supply $280 \mathrm{MW}$ of electricity. The conclusion of their study was that the present AOTs established in the MONJU safety guidelines provide a sufficient safety margin. This assessment assumed that the target events had already occurred. The evaluation method assigned event probabilities of 1 to any subject included in the fault tree. The failure of a control rod at the insertion event was estimated with generic data acquired from control rod operating experience [8]. In this instance, the failure probability, which considers a common cause failure, should be analyzed further by changing the evaluation conditions.

The MONJU safety guidelines define the measures required at the time of discovery of one stuck control rod, which is a safety function failure. The guidelines allow the reactor to continue operation if surveillance testing within $24 \mathrm{~h}$ confirms the integrity of the other control rods. If the surveillance testing finds that another control rod is stuck, the guidelines demand manual reactor trip operation.

In the present study, CDF was applied as an index to evaluate the applicability of the 24 $\mathrm{h}$ completion time for surveillance testing. First, in the process to estimate the probability of a control rod insertion failure, the analysis conditions were changed by the fact that one stuck rod is discovered. It is necessary to calculate the conditioned core damage frequency for the control rod insertion failure probability that was recalculated appropriately for the modified plant status. We reviewed recent research for a reference pertaining to assumptions in the calculation process for control rod insertion failure probability and for re-evaluation under such a condition. There are some studies about control rod insertion failure probability that considered its multiplicity.

According to the International Atomic Energy Agency (IAEA) database for research reactors [9], the failure rate for a control rod was estimated as $3 \times 10^{-6} / \mathrm{d}$ from one mechanical failure experienced in 15,940 demands from several research reactors. On the basis of the IAEA database for research reactors mentioned above, for the Greek research reactor Demokritos, Aneziris et al. estimated the failure rate of one rod as $2.28 \times 10^{-5} / \mathrm{h}$ and that of all five rods as $2.28 \times 10^{-6} / \mathrm{h}$ [10]. Bassi et al. [11] reported level 1 PSA for a gas-cooled fast reactor. In the study, the failure rate of a control rod and electromagnet was estimated as $1.27 \times 10^{-3} / \mathrm{d}$ on the basis of three common databases: EIREDA, a compilation of feedback from French pressurized water reactors; T-BOOK 6, related to Scandinavian light water reactors, and the EG\&G-gas, related to gas-cooled reactors. In addition, common cause failure parameters were also estimated from operational feedback from French and German light water reactors. On the basis of the IAEA database for research reactors, Faghihi et al. [12] evaluated the frequency of a stuck rod as $6.44 \times 10^{-5} / \mathrm{h}$ to quantify the initiating event frequency [9]. Eide and Calley [13] evaluated the probability of failure upon insertion or detachment of the control and safety rods/diverse safety rods and drive assembly as $3 \times 10^{-5} / \mathrm{d}$ on the basis of the Nuclear Computerized Library for Assessing Reactor Reliability (NUCLARR). Mladin analyzed the control rod failure rate by comparing the operational experience of the Romanian TRIGA steady state $14 \mathrm{MW}$ reactor [14] with the IAEA reliability database for research reactors. From the results of Mladin's study, the control rod failure rate of the Romanian TRIGA reactor was estimated as about 1 $\times 10^{-4} / \mathrm{h}$. In particular, the control rod failure probability was estimated from actual failure experiences and it ranged from $1 \times 10^{-6} / \mathrm{d}$ to $1 \times 10^{-3} / \mathrm{d}$. However, no studies were found in 
which the analysis conditions had to be changed and the result of re-evaluation involved control rod function failure experiences. On the other hand, there are methods to evaluate whether the completion time is appropriate. Incremental conditioned core damage probability (ICCDP) can be applied on the basis of conditional core damage frequency by considering the control rod insertion failure probability and a completion time of $24 \mathrm{~h}$. The obtained value of ICCDP can be compared with the risk threshold in NRC RG 1.177 [3].

This paper describes a method for estimating conditional core damage probability after the observation of a stuck control rod. Moreover, the evaluation results of applying this method to MONJU are presented.

\section{Abbreviations}
AOT : Allowed Outage Time
ATWS : Anticipated Transient Without Scram
BSS : Backup Shutdown System
CCRs : Coarse Control Rods
CDF : Core Damage Frequency
FCRs : Fine Control Rods
ICCDP : Incremental Conditioned Core Damage Probability
LCO : Limiting Conditions of Operation
MSS : Main reactor Shutdown System
PSA : Probabilistic Safety Assessment

\section{Evaluation Method}

According to the PSA analytical models of MONJU, the control rod insertion failure probability value has been calculated as $1 \times 10^{-8} / \mathrm{d}$ as described in section 2.1 . Figure 1 illustrates the anticipated transient without scram (ATWS) event tree and the branch of control rod insertion. This failure probability value, which means the probability of failing to insert the necessary number of control rods, has been applied to the heading after reactor trip breaker opening or successful accident management for reactor trip.

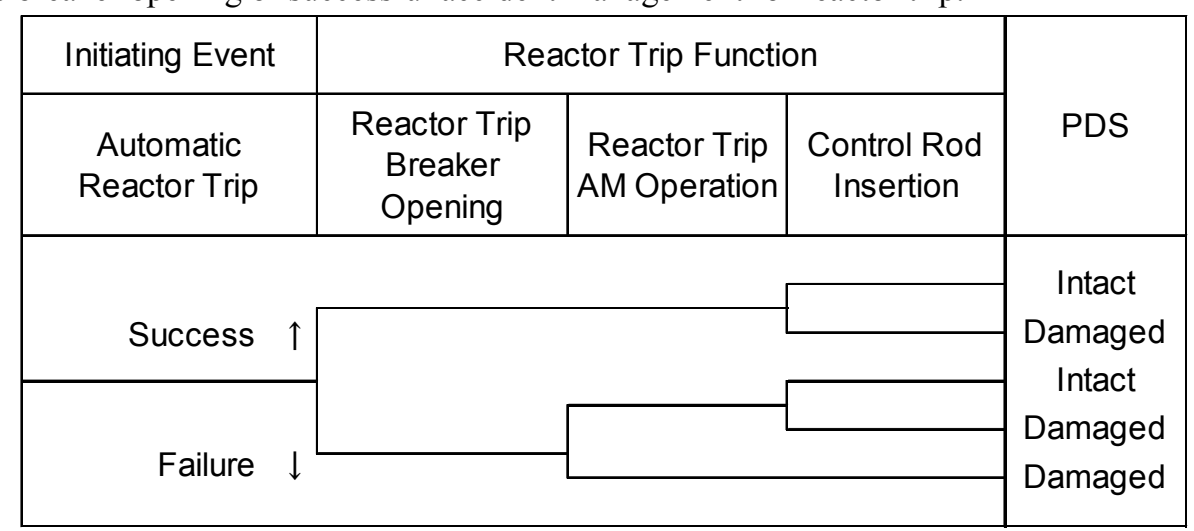

Fig. 1 ATWS event tree for automatic reactor trip

This event sequence includes control rod insertion failure reaching core damage directly; that is, the heading of control rod insertion applies only to the ATWS event trees. In this study, variations of core damage risk are evaluated from the result of the CDF recalculation by changing this value of control rod insertion heading. The fundamental knowledge necessary to calculate this failure probability is described below.

\subsection{Calculation of Control Rod Insertion Failure Probability}

In the level 1 PSA of MONJU, the failure probability per insertion of one control rod is calculated on the basis of the insertion performance number, which is evaluated as follows. 
As shown in Table 1, the insertion performance number includes the number of successful insertion results attained during the mock-up test of the control rod drive system. Based on the number of successful insertions, the average failure probability of insertion was calculated by applying Bayesian estimation along with Jeffrey's noninformative prior distribution.

This formula calculates the average value described below.

$$
u=\frac{x+0.5}{n+1}
$$

where $u$ is the average probability of one rod insertion failure, $x$ is the number of failures, and $n$ is the number of trials.

Table 1 Insertion failure probability of one rod

\begin{tabular}{crrrrrr} 
Data Source & $\begin{array}{c}\text { Number of } \\
\text { Failures: }\end{array}$ & $\begin{array}{c}\text { Number of } \\
\text { Trials:n }\end{array}$ & $\begin{array}{c}\text { Upper } \\
\text { Limit }\end{array}$ & Average & $\begin{array}{c}\text { Lower } \\
\text { Limit }\end{array}$ & Variance \\
\hline mock-up test Phase 1 & 0 & 2900 & $6.6 \mathrm{E}-04$ & $1.7 \mathrm{E}-04$ & $6.8 \mathrm{E}-07$ & $5.9 \mathrm{E}-08$ \\
\hline mock-up test Phase 2 & 0 & 6130 & $3.1 \mathrm{E}-04$ & $8.2 \mathrm{E}-05$ & $3.2 \mathrm{E}-07$ & $1.3 \mathrm{E}-08$ \\
\hline mock-up test for Joyo & 0 & 1542 & $1.2 \mathrm{E}-03$ & $3.2 \mathrm{E}-04$ & $1.3 \mathrm{E}-06$ & $2.1 \mathrm{E}-07$ \\
\hline Total & 0 & 10572 & $1.8 \mathrm{E}-04$ & $4.7 \mathrm{E}-05$ & $1.9 \mathrm{E}-07$ & $4.5 \mathrm{E}-09$ \\
\hline
\end{tabular}

The necessary number of control rod insertions required to shutdown the reactor has been evaluated as eight of ten rods in the main reactor shutdown system (MSS) and as three of six rods in the backup shutdown system (BSS). These premises are determined from the result of evaluating the reactivity worth of various control rod insertion patterns targeted in the equilibrium core.

The probability of insertion failure considering a common cause failure was evaluated by the multiple Greek letter (MGL) method [15]. The simultaneous insertion failure rate of any number of control rods was obtained by Eqs. (2) and (3). MGL parameters have been determined from the $\alpha$ factor in NUREG/CR-5500 Vol. 2 [8], which uses the operating experience of Westinghouse-designed plants as a data source.

Operation testing of the control rods was assumed to not shift the timing of the test; that is, nonstaggered testing conditions were applied. The $\alpha$ factor was converted to the MGL parameter by using Eqs. (4) and (5).

The calculated MGL parameters are shown in Table 2. The header row of Table 2 indicates the total number of components and the first column represents the Greek letter corresponding to the number of components that fail simultaneously.

$$
\begin{aligned}
& Q_{k}=\frac{1}{{ }_{m-1} C_{k-1}} \times\left(\prod_{i=1}^{k} \rho_{i}\right) \times\left(1-\rho_{k+1}\right) \times Q_{t} \quad \ldots \ldots . . . \cdots \\
& \rho_{1}=1, \rho_{2}=\beta, \rho_{3}=\gamma, \rho_{4}=\delta, \cdots, \rho_{m+1}=0 \quad \text { ・ } \cdot \cdots \cdot \cdots \cdot \cdot \cdot(3) \\
& \frac{k}{\alpha_{t}} \times \alpha_{k}=\left(\prod_{i=1}^{k} \rho_{i}\right) \times\left(1-\rho_{k+1}\right) \quad \text {. } \quad . . \cdots \cdot \cdot \cdots \cdot(4) \\
& \rho_{1}=1, \quad \rho_{2}=\beta=1-\frac{1}{\alpha_{t}} \times \alpha_{1}=\frac{\sum_{i=2}^{m} i \times \alpha_{i}}{\sum_{i=1}^{m} i \times \alpha_{i}} \\
& \cdot \rho_{k}=\frac{\sum_{i=k}^{m} i \times \alpha_{i}}{\sum_{i=k-1}^{m} i \times \alpha_{i}}
\end{aligned}
$$


where

$Q_{t}=$ total component failure probability,

$Q_{k}=$ simultaneous component failure probability of $k$ out of $m$ system,

$\alpha=\alpha$ factor,

$\rho \quad=$ MGL parameter.

Table 2 Converted MGL parameters

\begin{tabular}{lrrrrrrrrr} 
& 2 & 3 & 4 & 5 & 6 & 7 & 8 & 9 & 10 \\
\hline $1-\beta$ & $8.93 \mathrm{E}-01$ & $8.25 \mathrm{E}-01$ & $7.21 \mathrm{E}-01$ & $6.51 \mathrm{E}-01$ & $6.11 \mathrm{E}-01$ & $5.85 \mathrm{E}-01$ & $5.67 \mathrm{E}-01$ & $5.52 \mathrm{E}-01$ & $5.40 \mathrm{E}-01$ \\
\hline$\beta$ & $1.07 \mathrm{E}-01$ & $1.75 \mathrm{E}-01$ & $2.79 \mathrm{E}-01$ & $3.49 \mathrm{E}-01$ & $3.89 \mathrm{E}-01$ & $4.15 \mathrm{E}-01$ & $4.33 \mathrm{E}-01$ & $4.48 \mathrm{E}-01$ & $4.60 \mathrm{E}-01$ \\
\hline$\gamma$ & & $2.12 \mathrm{E}-01$ & $3.54 \mathrm{E}-01$ & $5.76 \mathrm{E}-01$ & $6.98 \mathrm{E}-01$ & $7.73 \mathrm{E}-01$ & $8.24 \mathrm{E}-01$ & $8.52 \mathrm{E}-01$ & $8.72 \mathrm{E}-01$ \\
\hline$\delta$ & & & $2.75 \mathrm{E}-01$ & $3.36 \mathrm{E}-01$ & $5.52 \mathrm{E}-01$ & $6.71 \mathrm{E}-01$ & $7.45 \mathrm{E}-01$ & $8.10 \mathrm{E}-01$ & $8.52 \mathrm{E}-01$ \\
\hline$\varepsilon$ & & & & $3.11 \mathrm{E}-01$ & $3.34 \mathrm{E}-01$ & $5.57 \mathrm{E}-01$ & $6.64 \mathrm{E}-01$ & $7.29 \mathrm{E}-01$ & $7.87 \mathrm{E}-01$ \\
\hline$\mu$ & & & & & $3.38 \mathrm{E}-01$ & $3.19 \mathrm{E}-01$ & $5.50 \mathrm{E}-01$ & $6.43 \mathrm{E}-01$ & $7.11 \mathrm{E}-01$ \\
\hline
\end{tabular}

It is also necessary to consider the correlation of uncertainty with each data point. Therefore, according to the following equation, the method of moments was used for the uncertainty propagation calculation by assuming a lognormal distribution.

The average lognormal distribution is

$$
E(X)=e^{\left(\mu+\frac{\sigma^{2}}{2}\right)}
$$

where

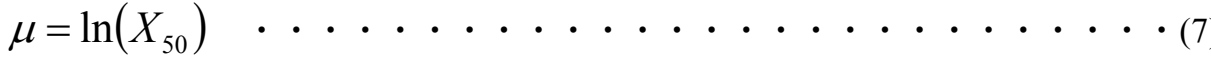

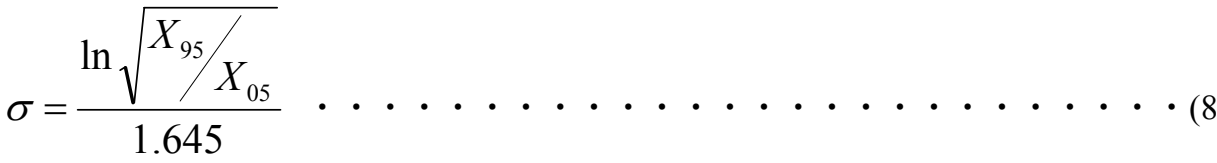

$\mathrm{X} 50=50 \%$ probability value,

$\mathrm{X} 05=5 \%$ probability value,

X95 $=95 \%$ probability value.

In this study, the lognormal distribution of 5, 50, and $95 \%$ values, obtained as the product of two data points, is the average value calculated after propagating uncertainty in relation to the above formula. These 5, 50, and 95\% values are determined on the basis of an error factor, which is estimated by an engineering approach. The relationships of these values are described below.

$$
\begin{aligned}
& X_{50}=\exp (\mu)=\sqrt{X_{05} \times X_{95}} \cdot \cdots \cdot \cdots \cdot \cdots \cdot(9) \\
& E F=\sqrt{X_{95} / X_{05}}=\exp (1.645 \sigma) \text {. . . . . . . . . . . . (10) }
\end{aligned}
$$

From the above calculation results, the average value of $1 \times 10^{-8}(/ \mathrm{d})$ has been applied as the probability of one rod insertion failure. 


\subsection{Analysis Conditions of CDF and ICCDP}

The LCO in the safety guidelines of MONJU is that the main reactor shutdown rods neither malfunction nor stick. In this paper, one stuck control rod is assumed to be inclusive of malfunction and hence the case of a stuck control rod was evaluated as representative. According to the safety guidelines, if one stuck control rod is discovered in the MSS, within $24 \mathrm{~h}$, it must be verified that no other control rods are stuck. If no other rods are stuck, the reactor can continue operation. Thus, the state of the plant should be evaluated considering the following cases.

1) One control rod is stuck.

2) No other stuck control rod is confirmed after the discovery of the first stuck control rod.

3) Discovery of two stuck control rods.

Control rod insertion failure probability was modeled as the final heading of the ATWS event tree, as shown in Fig. 1. The insertion failure probability of three or more rods out of all 10 rods in the MSS by considering a common cause failure is assumed to be caused by coarse control rods, because this is a dominant insertion failure case. Therefore, the probability of three or more coarse control rod insertion failures in the three plant states mentioned above was applied to calculate various core damage frequencies, as shown in Table 3.

Table 3 Analysis conditions

\begin{tabular}{lccc}
$\begin{array}{l}\text { LCO and Required } \\
\text { Measure }\end{array}$ & $\begin{array}{l}\text { BSS failure } \\
\text { probability of } 1 \\
\text { rod (/d) }\end{array}$ & $\begin{array}{l}\text { Total number } \\
\text { of failures }\end{array}$ & $\begin{array}{l}\text { MSS failure } \\
\text { probability of } \\
1 \text { rod }(/ \mathrm{d})\end{array}$ \\
\hline Ref.Case & $5.0 \mathrm{E}-05$ & $3 / 10$ & $5.0 \mathrm{E}-05$ \\
\hline $\begin{array}{l}1 \text { rod stuck } \\
\text { discovered in MSS }\end{array}$ & $1.5 \mathrm{E}-04$ & $2 / 9$ & $1.0 \mathrm{E}+00$ \\
\hline $\begin{array}{l}\text { Confirmation of no } \\
\text { other rods stuck }\end{array}$ & $1.5 \mathrm{E}-04$ & $2 / 9$ & $1.5 \mathrm{E}-04$ \\
\hline $\begin{array}{l}2 \text { rods stuck } \\
\text { discovered in MSS }\end{array}$ & $2.5 \mathrm{E}-04$ & $1 / 8$ & $1.0 \mathrm{E}+00$ \\
\hline
\end{tabular}

As shown in Table 1, the insertion failure probability of one control rod was calculated as $5 \times 10^{-5} / \mathrm{d}$ on the basis of the result of a control drive system mock-up test. This value was estimated from the number of zero insertion failures over the total insertion number of the test. On the other hand, the number of insertion failures when one stuck control rod was found is not zero. Therefore, the insertion failure probability of one control rod was calculated on the basis of the number of failures $x$ equaling 1 in Eq. (1).

A correlation of uncertainty was considered for the probability of one control rod insertion failure and the common cause failure rate (i.e., the ratio of any number of insertion failures to the total number of control rods). Uncertainty of insertion failure probability depends on the probability distribution of one type of data. Therefore, the correlation is not considered when one stuck rod is found.

In addition, after confirming the operation of the other control rods, insertion failure probability was updated by applying the number of stuck rods. The fraction of common cause failure was considered its correlation of uncertainty. The formula for the calculation is shown as follows.

$$
P=P_{M} F_{M} * P_{B} * F_{B} \ldots \ldots \ldots \ldots \ldots \ldots
$$




$$
F=\sum_{k=1}^{m}{ }_{m-1} C_{k-1} \times Q_{k} \ldots \ldots \ldots \ldots \ldots
$$

where

$P=$ event probability under the heading of control rod insertion,

$F=$ fraction of common cause failure,

$P_{M}=$ insertion failure probability of one rod in the MSS,

$F_{M}=$ fraction of common cause failure in the MSS,

$P_{B}=$ insertion failure probability of one rod in the BSS,

$F_{B}=$ fraction of common cause failure in the BSS.

The correlation of uncertainty was considered with $F_{M}$ and $F_{B}$ when one stuck rod was discovered. Thus, the calculated failure probabilities of control rod insertion are shown in Table 4 .

Table 4 Event probability under the heading of control rod insertion

\begin{tabular}{lc}
$\begin{array}{l}\text { LCO and Required } \\
\text { Measure }\end{array}$ & $\begin{array}{c}\text { Insertion failure } \\
\text { probability }(\mathrm{d})\end{array}$ \\
\hline Ref.Case & $1.0 \mathrm{E}-08$ \\
\hline $\begin{array}{l}1 \text { rod stuck discovered } \\
\text { in MSS }\end{array}$ & $5.0 \mathrm{E}-05$ \\
\hline $\begin{array}{l}\text { Reconfirmation of no } \\
\text { other rods stuck }\end{array}$ & $1.1 \mathrm{E}-07$ \\
\hline $\begin{array}{l}2 \text { rods stuck discovered } \\
\text { in MSS }\end{array}$ & $4.4 \mathrm{E}-04$ \\
\hline
\end{tabular}

According to NRC RG 1.177 [3], incremental conditional core damage probability (ICCDP) is defined as in Eqs. (13) and (14). Completion time can be considered as AOT in Eq. (13) because the core damage risk remains higher during this time. In addition, the risk threshold was determined as $5 \times 10^{-7}$; therefore, the completion time equivalent to the threshold can be calculated.

$$
\triangle C D F=R\left(p_{i}=1\right)-R_{0} \ldots \ldots \ldots \ldots \ldots
$$

where $R\left(p_{i}=1\right)$ is the conditional CDF and $R_{0}$ is the baseline CDF. Then,

$$
I C C D P=\triangle C D F \times A O T / 8760 \ldots \ldots \ldots(14)
$$

\section{Analysis Result and Discussion}

The result of the calculated CDF fraction $R\left(p_{i}=1\right) / R_{0}$ is shown in Table 5. CDF varied depending on the conditions stated in the safety guidelines. The CDF when one rod was stuck increased by about 290 times. The completion time equivalent of less than $5 \times 10^{-7}$ of ICCDP, which is the risk acceptance criteria indicated by NRC RG 1.177 [3], was estimated within $76 \mathrm{~h}$ by using the above CDF. If the measures stated in the current safety guidelines are not completed within $24 \mathrm{~h}$, then the reactor must be shutdown, ordinarily within $6 \mathrm{~h}$. The duration of operation required in this case is $30 \mathrm{~h}$, which is sufficiently short compared to the $76 \mathrm{~h}$. Therefore, the core damage risk to this completion time was evaluated as being below the acceptance criteria. 
Table 5 CDF fraction

\begin{tabular}{lcc}
$\begin{array}{l}\text { LCO and Required } \\
\text { Measure }\end{array}$ & CDF fraction & $\begin{array}{c}\text { Completion time to } \\
\text { ICCDP<5E-7(h) }\end{array}$ \\
\hline $\begin{array}{l}\text { Ref.Case } \\
\text { r rod stuck discovered } \\
\text { in MSS }\end{array}$ & $1.0 \mathrm{E}+00$ & - \\
\hline $\begin{array}{l}\text { Reconfirmation of no } \\
\text { other rods stuck }\end{array}$ & $2.9 \mathrm{E}+02$ & $7.6 \mathrm{E}+01$ \\
\hline $\begin{array}{l}2 \text { rods stuck discovered } \\
\text { in MSS }\end{array}$ & $1.3 \mathrm{E}+00$ & $6.3 \mathrm{E}+04$ \\
\hline
\end{tabular}

As shown in Figure 2, the solid line shows the variation in the case that no other stuck control rod was confirmed in the MSS within $24 \mathrm{~h}$ after discovering one stuck rod and reactor operation was continued.

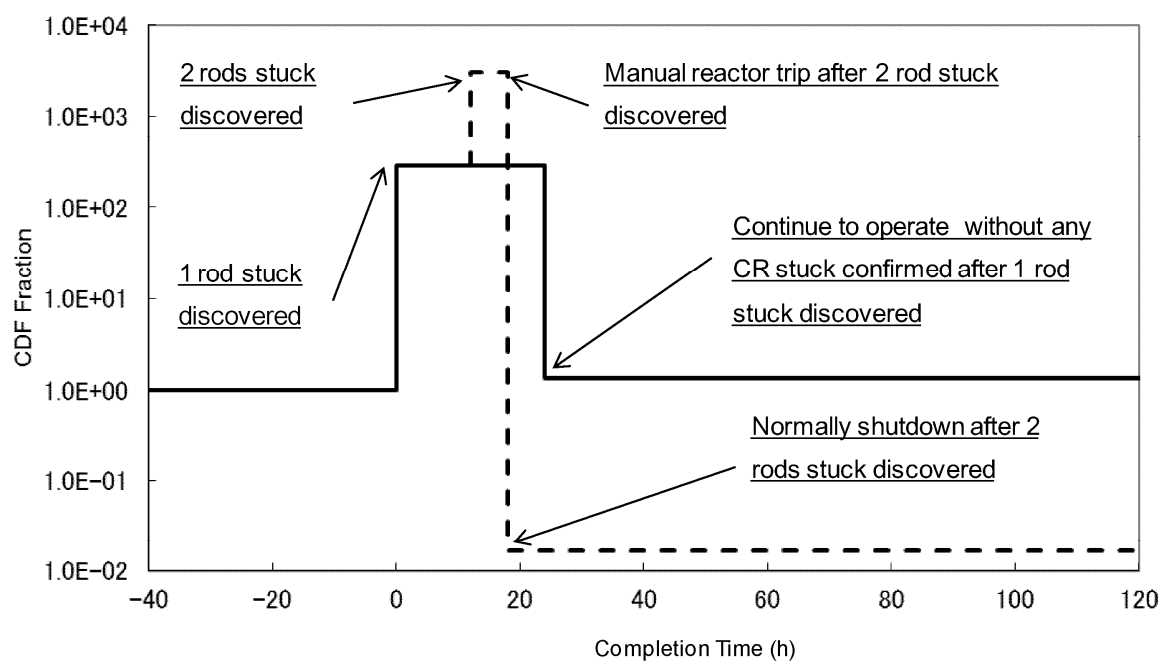

Fig. 2 CDF fraction on LCO

As shown in Table 5, CDF increased by about 1.3 times when it was confirmed that no other control rods were stuck. In this case, the completion time equivalent of less than $5 \times$ $10^{-7}$ of ICCDP was estimated as more than $60,000 \mathrm{~h}$. Therefore, measures for reactor operation continuance were reasonable in terms of the risk acceptance criteria.

Moreover, when two stuck rods were discovered, the safety guidelines provide the measures to open the reactor trip breaker as soon as possible. The CDF in this case is to be evaluated in the event tree shown in Figure 3. The conditioned core damage probability per reactor trip breaker opening is equal to the control rod insertion failure probability, which has a value of about $4.4 \times 10^{-4}$ from Table 4 . This is because CDF was increased owing to the open state of the reactor trip breaker, which increases the common cause failure probability of control rod insertion. Hence, the ordinary plant shutdown procedures, which are the measures in this case, can be safer than a manual reactor trip. The conditional core damage probability in the case of an ordinary plant shutdown can be evaluated by the event tree shown in Figure 4. The accident sequence is a loss of decay heat removal function after reactor shutdown in that all heat cooling systems are available. This conditional core damage probability for each shutdown was estimated as approximately 0.01 times of normal operation. 


\begin{tabular}{|c|c|c|}
\hline Initiating Event & Reactor Trip Function & \multirow{2}{*}{ PDS } \\
Other Causes & Control Rod Insertion & \\
\hline Success $\uparrow$ & \multirow{2}{*}{ Intact } \\
\cline { 1 - 1 } Failure $\downarrow$ & Damaged \\
\hline
\end{tabular}

Fig. 3 ATWS event tree for reactor trip due to other causes

Figure 2 shows the variation in the conditional core damage probability based on the above discussion. The dotted line indicates the discovery of two stuck rods followed by ordinary plant shutdown. In this case, the CDF due to reactor trip is about 1000 times larger than the ICCDP when ordinary plant shutdown is performed within $6 \mathrm{~h}$. Therefore, the core damage risk can be decreased markedly by changing the measures from manual trip to ordinary plant shutdown operations.

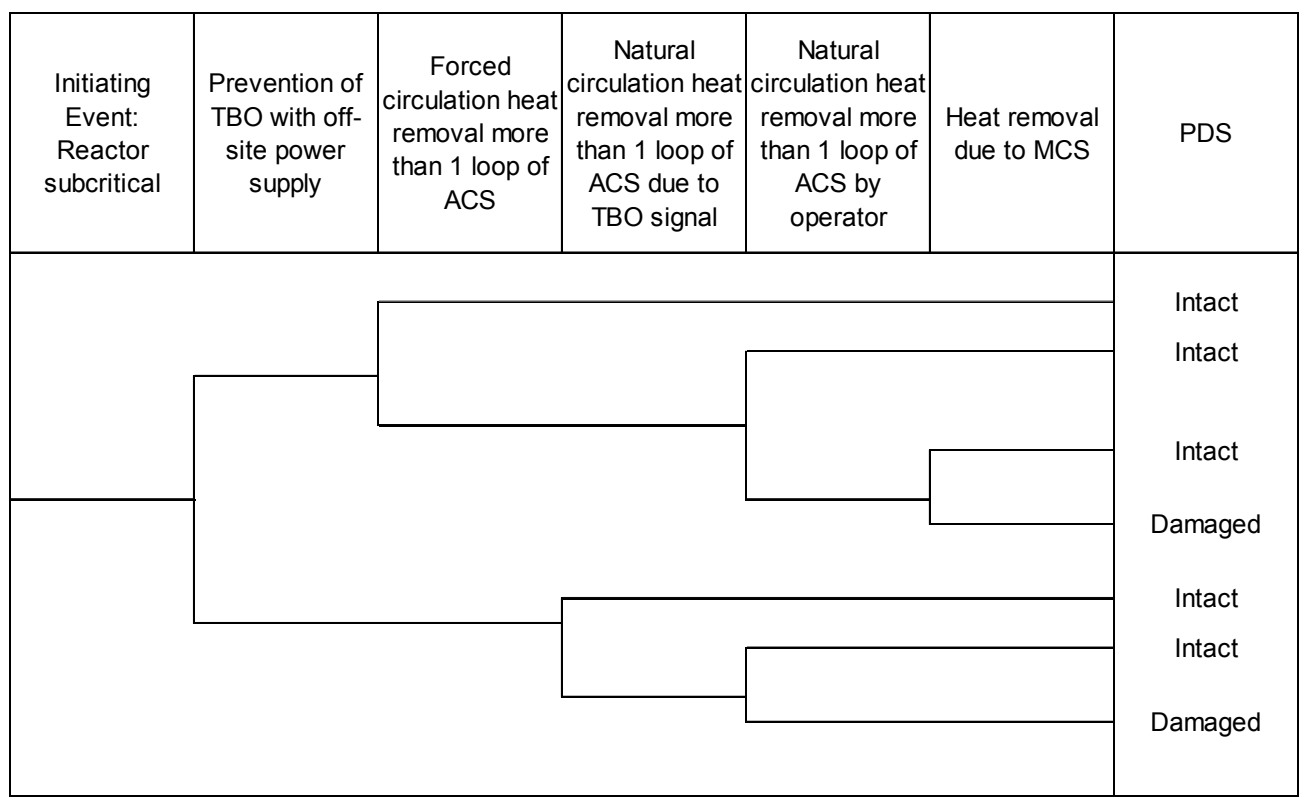

Fig. 4 Decay heat removal event tree

Next, operational continuity of the reactor is considered. MONJU contains two kinds of control rods: automatic fine control rods (FCRs) and manual coarse control rods (CCRs). Therefore, it is necessary to consider both types of rods. FCRs will be withdrawn to compensate for reactor power due to burnup as needed. On the other hand, CCRs will be withdrawn by an amount equivalent to power compensation by FCRs week by week. Furthermore, control rod deviation will be limited to $20 \mathrm{~mm}$ or less by the safety interlock circuit. Thereafter, power compensation will be restricted within a week at least when an FCR becomes stuck. On the other hand, it will be difficult to maintain the rated power after two weeks in the case where a CCR is stuck.

Thus, the decision as to whether reactor operation must be continued should be made by considering the prospects of repairing a stuck rod within the allowed operation time.

\section{Conclusion}

The plant status variations that affect the LCO for control rod function failure by sticking were analyzed, and the core damage frequency was re-evaluated on the basis of the variations. The evaluation result obtained by using ICCDP indicates the adequacy of the required measure and its completion time. In addition, the influence of the current measures 
on the conditional core damage probability was assessed, and some prospects were clarified for further consideration.

\section{References}

[1]. US Nuclear Regulatory Commission, "Standard Technical Specifications Westinghouse Plants,” NUREG-1431,Vol.1, Rev. 3.0, 2004

[2]. US Nuclear Regulatory Commission, "An Approach for Using Probabilistic Risk Assessment in Risk-Informed Decisions on Plant-Specific Changes to the Licensing Basis," Regulatory Guide 1.174, 1998.

[3]. US Nuclear Regulatory Commission, "An Approach for Plant-Specific, Risk-Informed Decision making : Technical Specifications,” RG1.177, 2002

[4]. NEI06-09, "Risk-Informed Technical Specifications Initiative 4b Risk-Managed Technical Specifications (RMTS) Guidelines," 2006

[5]. NUMARC93-01, "Industry Guideline for Monitoring the Effectiveness of Maintenance at Nuclear Power Plants," 2000

[6]. K. Kurisaka and T. Arakawa., "Study on risk-informed determination method of allowed outage time in fast reactor systems" (in Japanese), 2005

[7]. M.Sotsu and K.Kurisaka, "Evaluation of MONJU Core Damage Risk with Change of AOT Using Probabilistic Method" Journal of Power and Energy Systems, 2010

[8]. Eide, S.A., Beck, S.T., Calley, M.B., Galyean, W.J., Gentillon, C.D., Kherica, S.T., Novack, S.D., Wierman, T.E.,"Reliability Study: Westinghouse Reactor Protection System, 1984-1995”, NUREG/CR-5500 Vol.2, 1999

[9]. International Atomic Energy Agency, "Generic component reliability data for research reactor PSA”, IAEA-TECDOC-930, 1997

[10]. O.N. Aneziris, C. Housiadas, M. Stakakis, I.A. Papazoglou, "Probabilistic safety analysis of a Greek Research Reactor", Annals of Nuclear Energy 31 481-516, 2004

[11]. C. Bassi, Ph. Azria, M. Balmain, "Level 1 probabilistic safety assessment to support the design of the CEA 2400MWth gas-cooled fast reactor", Nuclear Engineering and Design 240 3758-3780, 2010

[12]. F. Faghihi, E. Ramezani, F. Yousefpour, S.M. Mirvakili, “ Level-1 probability safety assessment of the Iranian heavy water reactor using SAPHIRE software ", Reliability Engineering and System Safety 93 1377-1409, 2008

[13]. Eide, S.A., Calley, M.B., "Generic component failure data base", Proceedings of the International Conference on PSA, 1993

[14]. Daniela Mladin, Mirea Mladin, Marin Preda,1, Ilie Prisecaru, “ Multiple aspects of raw data collection and processing for Romanian TRIGA SSR ”, Nuclear Engineering and Design 240 1630-1643, 2010

[15]. A. Mosleh, K.N. Fleming, G.W Parry, H.M. Paula, D.M. Rasmuson and D.H. Worledge, "Procedures for treating common cause failures in safety and reliability studies," NUREG/CR 4780; Nuclear Regulatory Commission, EPRI NP-5613, Vol. 2 (January 1989). 